\title{
Induction of Allogeneic Unresponsiveness in Adult Dogs
}

\author{
ROLE OF NON-DLA HISTOCOMPATIBILITY VARIABLES IN CONDITIONING \\ THE OUTCOME OF BONE MARROW, KIDNEY, AND SKIN \\ TRANSPLANTATION IN RADIATION CHIMERAS
}

\author{
F. T. Rapaport, R. J. BachVaroff, K. Watanabe, H. Hirasawa, \\ N. Mollen, and J. W. Ferrebee, Department of Surgery, State \\ University of New York at Stony Brook, Stony Brook, New York 11794 \\ D. B. Amos, Division of Immunology, Duke University Medical Center, \\ Durham, North Carolina 27706 \\ F. D. CAnnon and D. A. Blumenstock, The Mary Imogene Bassett Hospital, \\ Cooperstown, New York 13326
}

\begin{abstract}
A B S T R A C T Exposure to supralethal total body irradiation and transplantation of bone marrow from a DLA- and pedigree-identical donor have regularly produced successful engraftment and the establishment of stable long-term chimerism in beagles of the Cooperstown colony. Bone marrow allografts performed in pairs of dogs bearing identical DLA haplotypes derived from different pedigree origins (i.e., different classes of the same haplotype) yielded two different results. Depending upon the particular haplotype pedigree combination used, such transplants either led to long-term chimerism or to failures of engraftment, secondary disease, and death of the recipients (i.e., pedigree-incompatible combinations).

Radiation chimeras given bone marrow from a DLAand pedigree-identical donor were challenged within 8-12 h after marrow transplantation with a renal allograft obtained from another DLA- and pedigree-identical donor. The recipients have remained unresponsive to such renal allografts and have survived indefinitely with normal renal function. In contrast, renal allografts obtained from donors bearing the same DLA haplotypes derived from pedigree-incompatible sources were rejected within 25-50 days after transplantation. The long-term surviving recipients have also been unresponsive to skin allografts obtained from their donor of marrow and the kidney donor. Skin grafts obtained from other DLA- and pedigree-identical dogs were rejected within 13-41 days, and grafts from DLA-incompatible donors survived for 10-25 days.
\end{abstract}

Received for publication 28 February 1977 and in revised form 28 September 1.977.
These results highlight the potential importance of genetically controlled histocompatibility determinants other than DLA in conditioning allograft reactivity. The determinants uncovered in the present study appear to be linked to the DLA complex, as demonstrated by the ability of the pedigree origins of DLA haplotypes present in individual dogs to serve as an effective marker system for such non-DLA antigen(s). The results also point to the potential usefulness of the early postirradiation period for the induction of allogeneic unresponsiveness in large adult mammals.

\section{INTRODUCTION}

The selectively bred lines of beagles maintained at The Mary Imogene Bassett Hospital in Cooperstown, N. Y., have provided an animal resource in which the transplantation of bone marrow from genotypically DLA-identical donors into irradiated littermate and(or) nonlittermate dogs bearing DLA haplotypes derived from the same pedigree origins can regularly produce long-term stable chimerism, with no evidence of a graftversus-host response at any time after transplantation (1-5). Challenge of the recipients with kidney (1), heart $(6)$, lung $(7)$, liver $(8,9)$, pancreas $(8,9)$, or skin (3) allografts obtained from the donor of marrow within 3-6 mo after irradiation and marrow reconstitution has demonstrated, in addition, that such chimeras are unresponsive to other allogeneic tissues obtained from that particular donor. The individual specificity of this state of tolerance was shown by the ability of the chimeras to reject skin grafts from other DLA-identical and(or) DLA-incompatible sources at a rate similar to that documented in untreated dogs (3). 
It is the purpose of this report to present a series of studies aimed at providing further insight into the role of genetically determined histocompatibility factors in affecting the outcome of transplantation in the canine species. A continuing series of bone marrow allografts in the Cooperstown colony between DLA-identical donor-recipient combinations bearing the same pedigree origins is used as the basic reference standard. The data are compared with the outcome of bone marrow allografts in pairs of animals which bear the same DLA haplotypes, but where such haplotypes were inherited from different pedigree sources. In the latter instance, some pedigree combinations have produced long-term stable chimerism, while certain other pairings have resulted regularly in failures of engraftment or secondary disease, and death of the recipients.

The results of this study also demonstrate that the state of allogeneic unresponsiveness produced by irradiation and bone marrow transplantation can be broadened to include not only tissues obtained from the donor of marrow, but also allografts from another donor, provided that $(a)$ transplantation of an organ from that other donor is performed within a short period $(20-24 \mathrm{~h})$ after irradiation, and $(b)$ the organ allograft is obtained from a donor bearing the same DLA haplotypes, derived from the same pedigree origins as the recipient. 12 of 14 renal allografts performed under such conditions currently survive with normal function for 113-949 days. In contrast, kidney transplants obtained from donors bearing DLA haplotypes which typed alike, but were derived from different pedigree origins, were rejected uniformly within 25-150 days. The long-term renal allograft recipients produced in this fashion were also unresponsive to skin allografts obtained from the donor of marrow and from the kidney donor. In contrast, skin grafts from other sources, including donors bearing the same DLA haplotypes, derived from the same pedigree origins as the recipient, were rejected at a rate similar to that observed in untreated animals (3).

\section{METHODS}

Selection of donors and recipients. The animals used throughout this study were adult male and female beagles of the Cooperstown colony weighing 17-27 lb. Donors and recipients were selected for transplantation on the basis of precise genotypic and pedigree data on the origins of each of their DLA haplotypes. In earlier studies of the inheritance of DLA antigen(s) in the Cooperstown colony (10), the gametic unit which transmits information for the DLA complex was defined as a haplotype. Each haplotype is believed to carry information for at least two and probably three serologically detectable $(\mathrm{SD})^{1}$ loci, and one LD locus, although there is still

${ }^{1}$ Abbreviations used in this paper: GVH, graft-versus-host; LD, lymphocyte surface detectable; MLC, mixed leukocyte culture; SD, serologically detectable. some ambiguity as to the precise number of genetic loci (SD or LD) which exist within the system (11).

The method of preparation of antisera and techniques for serological typing by the lymphocytotoxicity technique have been described in earlier reports $(12,13)$. Since $1972(14-17)$, such serological studies have been extended to include mixed leukocyte culture (MLC) tests for the identification of DLA-D products within the Cooperstown colony and in mongrel dogs. MLC tests were performed by a modification of the technique of Hartzman et al. (18). For this purpose, $1 \times 10^{5}$ purified peripheral blood lymphocytes from the responder animals were incubated with $3 \times 10^{5}$ mitomycin-treated stimulator cells in $0.2 \mathrm{ml}$ of RPMI 1640 medium, supplemented with $20 \mathrm{mmol} / \mathrm{ml}$ of L-glutamine, $100 \mathrm{IU} / \mathrm{ml}$ of penicillin, $50 \mu \mathrm{g} / \mathrm{ml}$ of streptomycin, $50 \mathrm{IU} / \mathrm{ml}$ of heparin, and $20 \%$ pooled dog serum obtained from 20 normal Cooperstown dogs. The mixtures of responding and mitomycin-treated cells were incubated in $5 \% \mathrm{CO}_{2}$ balanced air at $37^{\circ} \mathrm{C}$. On the 7 th day of incubation, $1 \mu \mathrm{Ci}$ of $\left[\right.$ methyl $={ }^{3} \mathrm{H}$ ] thymidine, $1.9 \mathrm{Ci} / \mathrm{mmol}$ (Schwarz/ Mann Div., Becton, Dickinson \& Co., Orangeburg, N. Y.) was added to each culture well. The cells in each culture were precipitated $16 \mathrm{~h}$ later using an automatic multiple harvester. The radioactivity of each sample was measured in a scintillation spectrometer. The degree of stimulation of responding lymphocytes was measured on the basis of the rate of incorporation of $\left[{ }^{3} \mathrm{H}\right]$ thymidine, expressed in counts per minute. All MLC tests were performed in quadruplicate, and informative tests were repeated at least once at a different time. In each experiment, individual aliquots of responder cells were cultured simultaneously with the appropriate controls and with stimulator cells obtained from DLA- and pedigree-identical donors, DLA-identical but pedigree-different donors, and DLA-incompatible donors. Two-way MLC tests were also performed in each experiment, utilizing the method described above, except that treatment of cells with mitomycin was omitted.

With the antisera currently in use in the Cooperstown colony, some haplotypes (represented symbolically in Table I as $\mathbf{\square}, \mathbf{\Theta}, \mathbf{-}$, and $\mathbf{\nabla})$ appear to carry more than two SD specificities; one haplotype (A) carries three defined specificities, and so far, the haplotype represented as "I" is detected by only one antigen. The superabundance of apparent antigens on some haplotypes (e.g., $\bullet$, which appears to transmit no less than five SD antigens) may be due to cross-reactivity or to the lack of ability to distinguish between public specificities which are common to several alleles and private specificities which have a very restricted distribution (10). Similarly, the detection of only one product of the "I" haplotype may be a consequence of the lack of completeness of the repertoire of available antisera.

The assignment of haplotypes to individual members of the Cooperstown colony was made possible through family studies (10). Some haplotypes appear to be particularly frequent in the colony, while others are rare. Haplotypes that appear to be serologically identical may, however, be biologically distinctive; as a consequence, the phenotype may fail to identify the genotype, and a given set of SD alleles may be associated, on haplotypes of distinctive ancestry or pedigree, with different sets of LD or other as yet undetected alleles. The uniqueness of these haplotypes has been established by detailed genealogic analysis of the pedigree of the whole Cooperstown colony, with serologic studies of 1,439 offspring of 307 consecutive matings, followed by bone marrow transplantation. The initial colony consists of 17 dogs that could have constituted 34 different DLA haplotypes. Of these 34 possible haplotypes, 23 have been declined; the remaining 11 haplotypes have either been lost from the colony through processes such as gene drift, or cannot be distinguished from 
the 23 recognized haplotypes. These 23 identifiable haplotypes fall into the six patterns represented symbolically as $\mathbf{\mathbf { v }} \boldsymbol{\mathbf { 0 }}, \mathbf{-}, \boldsymbol{\nabla}, \mathbf{|}$, and $\boldsymbol{\Delta}$, so that in certain instances, many haplotypes may have been assigned to the same phenotype on the basis of serology. From pedigree analysis, a unique assignment could then be given to each haplotype within a group, by adding a digit to the symbol ( $\Delta 5$, for example, indicates the fifth entry of this particular haplotype into the colony from one of the original founder animals). Because the animals came from the same (beagle) category, some degree of consanguinity may also be assumed in the ancestors. The exact number of unique haplotypes within a given group is therefore unknown. The minimum number of distinctive haplotypes is 6 , however, and the maximum is 23 , while the bone marrow transplantation studies outlined in this report indicate a value which lies between these extremes. Table II illustrates the current interpretation of the serologic and pedigree analysis of the DLA haplotypes observed in the colony, and lists the correspondence of the detected DLA antigens with the new nomenclature adopted at the 2nd International Symposium on Canine Immunogenetics (11).

Method of irradiation and bone marrow transplantation. The method of supralethal total body irradiation has been described previously (3). Briefly, each recipient was exposed to $1,2(1)-1,400 \mathrm{R}$ of continuous irradiation from two opposing ${ }^{60} \mathrm{Co}$ sources, at a source-to-target distance of $2-2.5 \mathrm{~m}$, with an exposure rate of 3-4 R/min. 12-18 h later, bone marrow was obtained from the prospectively selected donor and trans- planted into the recipient by a modification of the standard technique, consisting of the intravenous infusion of a suspension of 3-3.5 $\times 10^{9}$ nucleated bone marrow cells obtained by needle aspiration of the long bones and sternum of the donor (3). Leukocyte and platelet counts were performed three times weekly for the first 21 days and at weekly intervals thereafter. The return of leukocyte and platelet levels to normal values and the absence of any evidence of graft-versus-host $(\mathrm{GVH})$ disease were interpreted as evidence of successful engraftment and proliferation of the transplant (3). Persistence of chimerism was confirmed at regular intervals by the continuing presence of donor erythrocyte group antigens in the recipient and by the appearance of the sex characteristics of donor cells in the recipient's peripheral leukocytes.

Method of kidney and skin transplantation and criteria for the assessment of allograft survival. A renal allograft obtained from another donor was transplanted into each recipient within 8-12 hr after infusion of bone marrow. Two different categories of renal allograft donors were used. The first consisted of DLA-identical donors bearing DLA haplotypes derived from the same pedigree origins as the recipient and the corresponding donor of marrow. The second group consisted of kidneys obtained from a DLA-identical donor bearing DLA haplotypes derived from pedigree origins which differed from the origins of the DLA haplotypes present in the recipient and the donor of marrow. The method of kidney transplantation into the iliac fossa of the recipients and criteria for the diagnosis of allograft rejection have been described in

TABLE I

DLA Genotypes of the Initial Members of the Cooperstown Beagle Colony and Correspondence with the New International Nomenclature

\begin{tabular}{|c|c|c|c|c|}
\hline $\begin{array}{l}\text { Dog } \\
\text { no. }\end{array}$ & $\begin{array}{l}\text { Relationship between } \\
\text { individual animals }\end{array}$ & $\begin{array}{l}\text { Postulated } \\
\text { DLA } \\
\text { haplotypes }\end{array}$ & $\begin{array}{l}\text { Correspondence with new DLA } \\
\text { nomenclature (by haplotypes) }\end{array}$ & $\begin{array}{c}\text { Symbols for } \\
\text { each } \\
\text { genotype* }^{*}\end{array}$ \\
\hline $\mathrm{C} 6$ & Littermates & $\mathrm{gl} /$ "nul" & DLA-A2,B5/“nul”" & $\Delta 1 /$ "nul" \\
\hline C7 & & & DLA-A2,B5/DLA-A10,B13 & $\Delta 2 / a_{1}$ \\
\hline $\mathrm{Cl1}$ & Same sire as $\mathrm{C} 6, \mathrm{C} 7$ & $\mathrm{gl} / \mathrm{bkhfm}$ & DLA/A2,B5/DLA-A10,B13 & $\Delta 3 / \square 2$ \\
\hline 470 & Unrelated & $\mathrm{bkcdn} / \mathrm{X}$ & DLA-A7,B13/X,X & $1 / \mathrm{X}$ \\
\hline 684 & Unrelated & $\mathrm{gl} / \mathrm{X}$ & DLA-A2,B5/X,X & $\Delta 4 / \mathrm{X}$ \\
\hline 709 & Unrelated & $e / X$ & DLA-A3,B12 (or 6) $+/ \mathrm{X}, \mathrm{X}$ & $\mathbf{I l} / \mathbf{X}$ \\
\hline 794 & Unrelated & $\mathrm{gl} / \mathrm{bkhfm}$ & DLA-A2,B5/DLA-A10,B13 & $\Delta 5 / \square 5$ \\
\hline 1,000 & Unrelated & gl/bekm(f) & DLA-A2,B5/DLA-A7,B12 (or 6) $\ddagger$ & $\Delta 11 /=1$ \\
\hline 1,184 & Unrelated & $\operatorname{bekm}(\mathbf{f}) / \mathrm{X}$ & DLA-A7,B12 (or 6$)+/ \mathrm{X}, \mathrm{X}$ & $-2 / X$ \\
\hline 1,189 & Littermates & $\mathrm{gl} / \mathrm{X}$ & DLA-A2,B5/X,X & $\Delta 6 / \mathrm{X}$ \\
\hline 1,193 & Littermates & gl/glo & DLA-A2,B5/DLA-A3,B5 & $\Delta 7 / \nabla 1$ \\
\hline 1,196 & Unrelated & $\mathrm{bkcdn} / \mathrm{X}$ & DLA-A7,B13/X,X & $02 / \mathrm{X}$ \\
\hline 1,202 & Dam of 1,206 & $\mathrm{bkhfm} / \mathrm{X}$ & DLA-A10,B13/X,X & $\mathbf{a} / \mathrm{X}$ \\
\hline 1,206 & Offspring of 1,202 & $\mathrm{bkhfm} / \mathrm{gl}$ & DLA-A10,B13/DLA-A2,B5 & $\square 4 / \Delta 8$ \\
\hline 1,208 & Unrelated & $\mathrm{gl} / \mathrm{X}$ & DLA-A2,B5/X,X & $\Delta 9 / \mathbf{X}$ \\
\hline 1,209 & Unrelated & $\mathrm{gl} / \mathrm{X}$ & DLA-A2,B5/DLA-A3,B5 & $\Delta 10 / \nabla X$ \\
\hline 1,284 & Unrelated & bekm(f)/X & DLA-A7,B12 (or 6) $\mathfrak{t} / \mathbf{X}, \mathbf{X}$ & $-3 / \mathrm{X}$ \\
\hline
\end{tabular}

The symbols refer to the six different DLA haplotypes detected in the Cooperstown beagles. The numbers opposite to these haplotypes in the last column of this table refer to the different individual origins of each of these haplotypes. gl, $\mathbf{\Delta}$; bkhfm, $\mathbf{\square}$; bkcdn, $\mathbf{\bullet}$; e, |; bekm(f), -; glo, $\nabla$.

* The symbols listed in the last column refer to the different DLA haplotypes detected in the Cooperstown beagles ( $\mathrm{gl}, \mathrm{bkhfm}$, bkcdn, e, bekm(f), and glo). The numbers opposite each haplotype symbol refer to the individual origins of each of these haplotypes, i.e., the different parental lines or pedigrees from which such haplotypes are derived.

$\ddagger$ DLA-B 12 and 6 are extremely cross-reactive and are not yet separable by currently available antisera. 
TABLE II

Bone Marrow Transplantation in Prospectively Selected Irradiated DLA-Identical Beagles Bearing DLA Haplotypes Derived from the Same Original Ancestral (Pedigree) Sources

\begin{tabular}{|c|c|c|c|c|c|c|}
\hline \multirow[b]{2}{*}{ Donor } & \multirow{2}{*}{$\begin{array}{c}\text { Recip- } \\
\text { ient }\end{array}$} & \multirow[b]{2}{*}{ Relationship } & \multirow{2}{*}{$\begin{array}{c}\operatorname{DLA}(\mathrm{SD}) \\
\text { genotype donor } \\
\text { and recipient }\end{array}$} & \multicolumn{2}{|c|}{$\begin{array}{l}\text { Pedigree background of the DLA } \\
\text { genotype of }\end{array}$} & \multirow{2}{*}{$\begin{array}{c}\text { Survival of } \\
\text { bone marrou } \\
\text { transplant }\end{array}$} \\
\hline & & & & Donor & Recipient & \\
\hline & & & & & & days \\
\hline $25-33$ & $25-36$ & Littermates & bkcdn/gl & $1 / \Delta 7$ & $1 / \Delta 7$ & $>1,145$ \\
\hline $25-89$ & $25-85$ & & bkcdn/glo & $1 / \nabla 1$ & $\mathbf{O} / \mathbf{\nabla} 1$ & $>936$ \\
\hline $26-13$ & $26-11$ & & $\mathrm{gl} / \mathrm{glo}$ & $\Delta 10 / \nabla 1$ & $\Delta 10 / \nabla 1$ & $>906$ \\
\hline $26-40$ & $26-38$ & & bkhfim/bkhfm & $\square 4 / \square 4$ & $\square 4 / \square 4$ & $>704$ \\
\hline $25-45$ & $25-44$ & & bkcdn/bkhfm & $1 / \square 4$ & $1 / \square 4$ & $>695$ \\
\hline $23-23$ & $23-24$ & & $\mathrm{gl} / \mathrm{gl}$ & $\Delta \mathrm{l}(0 / \Delta \mathrm{l} 0$ or 1 & $\Delta 10 / \Delta 10$ or 1 & $>392$ \\
\hline $23-52$ & $23-54$ & & $\mathrm{gl} / \mathrm{glo}$ & $\Delta 3$ or $10 / \nabla 1$ & $\Delta 3$ or $10 / \nabla \mathbf{l}$ & $>316$ \\
\hline $23-56$ & $23-55$ & & $\mathrm{gl} / \mathrm{glo}$ & $\Delta 3$ or $10 / \nabla 1$ & $\Delta 3$ or $10 / \nabla 1$ & $>315$ \\
\hline $22-80$ & $22-82$ & & $\mathrm{gl} / \mathrm{gl}$ & $\Delta 10 / \Delta 3$ or 8 & $\Delta 10 / \mathbf{\Delta} 3$ or 8 & $>291$ \\
\hline $25-52$ & $25-43$ & Nonlittermates & bkhfm/bkhfm & $\square 4 / \square 2$ or 5 & $4 / \square 2$ or 5 & $>964$ \\
\hline $25-55$ & $25-42$ & & $\mathrm{bkhfm} / \mathrm{bkhfm}$ & $\square 4 / \square 2$ or 5 & $4 / \square 2$ or 5 & $>948$ \\
\hline $24-56$ & $24-64$ & & $\mathrm{bkhfm} / \mathrm{bkhfm}$ & $\square 2$ or $4 / \square 5$ & $\square 4 / \square 5$ & $>908$ \\
\hline 26-05 & $24-63$ & & bkhfm/bkhfm & $\square 4 / \square 4$ & $\square / \square 2$ or 4 & $>903$ \\
\hline $26-62$ & $26-77$ & & bkcdn/bkhfm & 1/ם4 & $1 / \square 4$ & $>6.36$ \\
\hline $23-46$ & $23-51$ & & bkhfm/bkhfm & $\square 4 / \square 2$ & $\square 4 / \square 2$ & $>338$ \\
\hline $25-96$ & $25-82$ & & $\mathrm{bkhfm} / \mathrm{gl}$ & $\square 4 / \Delta 9$ & $\square 4 / \Delta 9$ & $>310$ \\
\hline
\end{tabular}

detail previously (19). All recipients underwent removal of their own kidneys within 29-54 days after renal transplantation. Renal function tests were performed at periodic intervals in all recipients. Each surviving recipient was tested with skin allografts at 6 or more months after kidney transplantation. Skin grafts were obtained from four different sources, including: $(a)$ the donor of marrow; $(b)$ the kidney donor; $(c)$ another donor bearing DLA- and pedigree origin-identical DLA haplotypes; and $(d)$ a DLA-incompatible donor. The technique of skin grafting has been described previously (3). Briefly, it consists of the transplantation of full-thickness $2 \times 2-\mathrm{cm}$ segments of skin (3), using the panniculus carnosus layer as the graft bed in the recipient. All transplants are performed in duplicate and are examined daily after the 7 th postoperative day, using standard criteria for the diagnosis of allograft rejection (3).

\section{RESULTS}

\section{Background data; bone marrow}

transplantation in DLA-identical donor-

recipient pairs bearing DLA haplotypes

derived from the same pedigree origins

Table I outlines the DLA genotypes of the original 17 members of the Cooperstown colony. The symbols which appear in the last column refer to the different DLA haplotypes detected in this colony. The number opposite each haplotype refers to the specific individual source of each haplotype and corresponds to the original canine member of the Cooperstown colony from which it was derived (i.e., numbers are used to denote the specific pedigree or ancestral origin of each DLA haplotype in the dogs under study).
Table II presents a group of heretofore not reported additions to the base-line series of bone marrow transplants performed under conditions of DLA haplotype and pedigree identity within the Cooperstown colony since $1970(1-5)$. The series has grown at present to 22 littermate and 15 nonlittermate donor-recipient pairs, with successful engraftment and survival of the irradiated host in each of 37 consecutive instances. Persistence of chimerism was confirmed in informative pairs by the appearance of donor Swisher erythrocyte antigens and leukocyte sex characteristics in the blood cells of the recipient. No manifestations of GVH were observed in any of the animals.

\section{Bone marrow tranplantation in DLA-identical donor-recipient pairs bearing DLA haplotypes derived from different pedigree origins}

DLA haplotype pedigree differences associated with successful engraftment and long-term chimerism. Table III illustrates the results of bone marrow transplantation in donor-recipient pairs bearing the same DLA haplotypes, where such haplotypes were transmitted to each animal from a different pedigree source. The DLA haplotype pedigree combinations tested in this particular series included $\mathbf{\Delta} 3, \boldsymbol{\Delta} 7, \boldsymbol{\Delta} 10$, and $\mathbf{\square}$, 口4. Successful engraftment and establishment of chimerism occurred in all $\Delta 3, \Delta 7, \Delta 10$ donor-recipient combinations, with current survival of the recipients for $725,638,375,335,308,306,284,264$, and 261 days, 
TABLE III

Bone Marrow Transplantation in Prospectively Selected DLA-Identical Beagles Bearing DLA Haplotypes Derived from Different Original Ancestral (Pedigree) Sources: Donor-Recipient Combinations Associated with Successful Engraftment and Long-Term Chimerism

\begin{tabular}{|c|c|c|c|c|c|c|c|}
\hline \multirow[b]{2}{*}{ Donor } & \multirow{2}{*}{$\begin{array}{c}\text { Recip- } \\
\text { ient }\end{array}$} & \multirow{2}{*}{$\begin{array}{l}\text { Relation- } \\
\text { ship }\end{array}$} & \multirow{2}{*}{$\begin{array}{c}\text { DLA(SD) } \\
\text { genotype of donor } \\
\text { and recipient }\end{array}$} & \multicolumn{2}{|c|}{$\begin{array}{l}\text { Pedigree background of the DLA } \\
\text { genotype of }\end{array}$} & \multirow{2}{*}{$\begin{array}{c}\text { Haplotype } \\
\text { pedigree } \\
\text { differences }\end{array}$} & \multirow{2}{*}{$\begin{array}{c}\text { Survival of } \\
\text { bone marrow } \\
\text { transplant }\end{array}$} \\
\hline & & & & Donor & Recipient & & \\
\hline & & & & & & & days \\
\hline $24-67$ & $24-40$ & Litter- & bkedn/gl & $\bullet 1 / \Delta 3$ & $\bullet 1 / \Delta 10$ & $\Delta 3 \rightarrow \Delta 10$ & $>725$ \\
\hline $25-22$ & $25-25$ & mates & $\mathrm{gl} / \mathrm{gl}$ & $\Delta 7 / \mathbf{\Delta} 7$ & $\Delta \mathbf{\Delta} 10 / \mathbf{\Delta} 10$ & $\Delta \mathbf{\Delta} \rightarrow \mathbf{\Delta} 10$ & $>638$ \\
\hline $25-29$ & $25-90$ & & bkcdn/bkhfm & $\bullet 1 / \square 4$ & $\bullet 1 / \mathbf{q}^{2}$ & $\mathbf{\square} 4 \rightarrow \mathbf{\square} 2$ & $>579$ \\
\hline $23-31$ & $23-48$ & & bkhfm/bkhfm & Ф4/ロ4 & $\square 4 / \mathbf{a}^{2}$ & $\square 4 \rightarrow \square 2$ & $>469$ \\
\hline $24-78$ & $24-30$ & & bkhfm/bkhfm & $\square 4 / \mathbf{a}^{2}$ & $\mathbf{\square} / \mathbf{\square} 2$ & $\mathbf{\square} \rightarrow \mathbf{\square}$ & $>385$ \\
\hline $22-79$ & $22-77$ & & $\mathrm{gl} / \mathrm{gl}$ & $\Delta 10 / \mathbf{\Delta} 3$ & $\Delta 10 / \Delta 7$ or 10 & $\Delta 3 \rightarrow \mathbf{\Delta} 3$ or 10 & $>375$ \\
\hline 24-69 & $24-55$ & & $\mathrm{bkcdn} / \mathrm{gl}$ & $\bullet 1 / \Delta 3$ & $\bullet 1 / \Delta 7$ & $\Delta 3 \rightarrow \mathbf{\Delta} 7$ & $>335$ \\
\hline $23-44$ & $24-77$ & & $\mathrm{bkhfm} / \mathrm{bkhfm}$ & $\square 2 / \square 4$ & $\mathbf{\square} / \mathbf{\square} 4$ & $\square 2 \rightarrow \square 4$ & $>310$ \\
\hline $22-45$ & $22-93$ & & $\mathrm{gl} / \mathrm{gl}$ & $\Delta 10 / \mathbf{\Delta} 3,7$ or 10 & $\Delta \mathbf{\Delta} / \mathbf{\Delta} 3$ & $\Delta 10 \rightarrow \Delta \mathbf{\Delta}$ & $>308$ \\
\hline $22-54$ & $22-47$ & & $\mathrm{gl} / \mathrm{gl}$ & $\Delta 7 / \mathbf{\Delta} 3$ & $\Delta 10 / \mathbf{\Delta} 3,7$ or 10 & $\Delta 3 \rightarrow \mathbf{\Delta} 10$ & $>306$ \\
\hline $23-45$ & $23-57$ & & $\mathrm{gl} / \mathrm{gl}$ & $\Delta \mathbf{\Delta} / \mathbf{\Delta} 7$ & $\mathbf{\Delta} 10 / \mathbf{\Delta} 3$ & $\begin{array}{l}\Delta 7 \rightarrow \Delta 3 \\
\Delta 7 \rightarrow \Delta 10\end{array}$ & $>284$ \\
\hline $21-85$ & $21-82$ & & $\mathrm{gl} / \mathrm{gl}$ & $\Delta 7 / \mathbf{\Delta} 3$ & $\mathbf{\Delta} 10 / \mathbf{\Delta} 3,7$ or 10 & $\begin{array}{l}\Delta 3 \rightarrow \Delta 10 \\
\Delta 7 \rightarrow \Delta 10\end{array}$ & $>264$ \\
\hline $21-86$ & $21-84$ & & $\mathrm{gl} / \mathrm{gl}$ & $\Delta 7 / \mathbf{\Delta} 3$ & $\Delta 10 / \mathbf{\Delta} 3,7$ or 10 & $\begin{array}{l}\Delta 3 \rightarrow \Delta 10 \\
\Delta 7 \rightarrow \Delta 10\end{array}$ & $>261$ \\
\hline $23-30$ & $23-43$ & & $\mathrm{bkhfm} / \mathrm{bkhfm}$ & $\square 4 / \square 4$ & $\square 2 / \square 4$ & $\mathbf{\square} \rightarrow \mathbf{\square} 2$ & $>254$ \\
\hline
\end{tabular}

respectively, in nine consecutive instances. The same result occurred in $\square 2, \boldsymbol{\square}$ combinations, with survivals of $579,469,385,310$, and 254 days, respectively, in five animals. No evidence of GVH disease developed in any of the recipients. Review of the pedigree origins of DLA haplotypes $\Delta 3, \Delta 7$, and $\Delta 10$ (see Table II) indicates that the three founding members of the Cooperstown colony from which these haplotypes were inherited (dogs C11, 11-93, and 12-09) were unrelated animals. The same is true for the origins of DLA haplotypes $\square 2$ and $\square$ (dogs $C 11$ and 12-06), which were also unrelated.

DLA haplotype pedigrees associated with failure of engraftment and(or) acute secondary disease. The successful establishment of chimerism associated with bone marrow transplantation in $\Delta 3, \Delta 7, \Delta 10$, or $\mathbf{\square}$, प4 donor-recipient combinations (Table V) did not apply to certain other donor-recipient DLA haplotype pedigree relationships tested during the present study. As shown in Table IV, bone marrow allografts performed between dogs bearing DLA haplotypes $\Delta \mathbf{1}$ or $\Delta 8$ on the one hand, and $\Delta 3, \Delta 7$, or $\Delta 8$ on the other, produced failures of engraftment or acute secondary disease and death of the recipients within 7-40 days. The same result occurred in two 5 recipients of 4 marrow, which succumbed at 23 and 60 days, respectively.

The data presented in Tables III and IV indicate that the outcome of bone marrow transplantation in donor- recipient pairs which are otherwise indistinguishable by currently available DLA typing techniques is predictable on the basis of the DLA haplotype pedigree origins in such dogs. DLA- and pedigree-identical bone marrow allografts had uniform success, and transplants performed with $(\Delta 3 \rightleftharpoons \Delta 7 \rightleftharpoons \Delta 10)$ or within $(\square 2 \rightleftharpoons \square 4)$ combinations survived in similar fashion. In contrast, bone marrow allografts performed between $\Delta 1$ or $\Delta 8$ and $\Delta 3, \Delta 7$, or $\Delta 10$ dogs, or between $\square 2$ or $\square 4$ and $\square 5$ dogs failed. Preliminary studies in progress at this time suggest, in addition, that bone marrow allografts performed between $\Delta 1$ and $\Delta 8$ dogs are tolerated uneventfully.

These data point to the association of certain histocompatibility determinants other than currently detectable products of the DLA complex with certain DLA haplotypes, whose pedigree origins can serve as markers for such hitherto undetectable determinants. Such non-DLA determinants may or may not be shared by unrelated animals (such as C11, 11-93, and 12-09 in Table II, for example). Unrelated animals sharing "compatible" non-DLA determinants (as demonstrated by the success of bone marrow transplantation) might thus be considered as belonging to the same "group" of non-DLA products ( $\Delta 3, \Delta 7$, and $\Delta 10$, for example), in contrast to unrelated animals sharing "incompatible" determinants (such as $\Delta 1$ and $\Delta 8$ ), which might include a second group of such antigen(s) within the overall category of dogs bearing DLA haplotype $\boldsymbol{\Lambda}$. A 
TABLE IV

Bone Marrow Transplantation in Prospectively Selected Irradiated DLA-Identical Beagles Bearing DLH Haplotypes Derived from Different Original Ancestral (Pedigree) Sources: Donor-Recipient Combinations

Associated with Failures of Engraftment and (or) Acute Secondary Disease

\begin{tabular}{|c|c|c|c|c|c|c|c|c|}
\hline \multirow[b]{2}{*}{ Donor } & \multirow{2}{*}{$\begin{array}{c}\text { Recip- } \\
\text { ient }\end{array}$} & \multirow[b]{2}{*}{ Relationship } & \multirow{2}{*}{$\begin{array}{l}\text { DLA(SD) } \\
\text { genotype } \\
\text { of donor } \\
\text { and } \\
\text { recipient }\end{array}$} & \multicolumn{2}{|c|}{$\begin{array}{l}\text { Pedigree background of the } \\
\text { DLA genotype of }\end{array}$} & \multirow{2}{*}{$\begin{array}{l}\text { Haplotype } \\
\text { pedigree } \\
\text { differences }\end{array}$} & \multirow{2}{*}{$\begin{array}{c}\text { Fate of bone marrow } \\
\text { allograft }\end{array}$} & \multirow{2}{*}{$\begin{array}{l}\text { Survival } \\
\text { of recip- } \\
\text { ient }\end{array}$} \\
\hline & & & & Donor & Recipient & & & \\
\hline & & & & & & & & dayss \\
\hline $22-73$ & $21-58$ & Nonlittermate & $\mathrm{gl} / \mathrm{gl}$ & $\Delta \mathbf{1 0} / \mathbf{\Delta} 7$ & $\Delta 7 / \Delta 8$ & $\Delta 10 \rightarrow \Delta 8$ & Failure of engraftment & 19 \\
\hline $22-28$ & $22-12$ & Nonlittermate & $\mathrm{gl} / \mathrm{gl}$ & $\Delta 10 / \Delta 10$ & $\Delta 10 / \Delta 1$ & $\Delta 10 \rightarrow \Delta 1$ & Failure of engraftment & 11 \\
\hline $22-41$ & $22-53$ & Nonlittermate & $\mathrm{gl} / \mathrm{bkhfm}$ & $\Delta 3$ or $7 / \square 4$ & $\Delta 7 / \mathbf{Q} 5$ & $\square 4 \rightarrow \mathbf{\square}$ & Secondary disease & 60 \\
\hline $22-76$ & $22-80$ & Nonlittermate & $\mathrm{gl} / \mathrm{gl}$ & $\Delta 10 / \Delta 8$ & $\Delta 10 / \Delta 7$ or 10 & $\Delta 8 \rightarrow \Delta 7$ or 10 & Failure of engraftment & 12 \\
\hline $22-82$ & $22-81$ & Littermate & $\mathrm{gl} / \mathrm{gl}$ & $\Delta 10 / \Delta 8$ & $\Delta 10 / \Delta 3$ & $\Delta 8 \rightarrow \Delta 3$ & Failure of engraftment & 13 \\
\hline $24-82$ & $24-13$ & Nonlittermate & $\mathrm{gl} / \mathrm{bkhfm}$ & $\Delta 8 / \square 4$ & $\Delta 7 / \mathbf{a} 2$ & $\Delta 8 \rightarrow \mathbf{\Delta} 7$ & Failure of engraftment & 13 \\
\hline $19-51$ & $24-42$ & Nonlittermate & bkhfm/gl & $\square / \mathbf{\Delta} 3$ or 10 & $\mathbf{\square} 4 / \mathbf{\Delta} 3$ & $\square 4 \rightarrow \square 5$ & Secondary disease & 23 \\
\hline $25-00$ & $24-98$ & Littermate & $\mathrm{gl} / \mathrm{bkhfm}$ & $\Delta 8 / \square$ & $\Delta 3 / \square 4$ & $\Delta 8 \rightarrow \Delta 3$ & Failure of engraftment & 12 \\
\hline $25-(00$ & 24-99 & Littermate & $\mathrm{gl} / \mathrm{bkhfm}$ & $\Delta 8 / \square 4$ & $\Delta 3 / \square 4$ & $\mathbf{\Delta} 8 \rightarrow \dot{\Delta} 3$ & Failure of engraftment & 12 \\
\hline $25-97$ & $25-00$ & Nonlittermate & bkhfm/gl & $\mathbf{D} / \mathbf{\Delta} 3$ & $\mathbf{D} 4 / \Delta 8$ & $\Delta 3 \rightarrow \mathbf{\Delta} 8$ & Failure of engraftment & 7 \\
\hline $25-21$ & $25-20$ & Littermate & $\mathrm{gl} / \mathrm{gl}$ & $\Delta 10 / \Delta 1$ & $\Delta 10 / \Delta 10$ & $\Delta 1 \rightarrow \Delta 10$ & Failure of engraftment & 11 \\
\hline $25-70$ & $26-26$ & Nonlittermate & $\mathrm{gl} / \mathrm{gl}$ & $\Delta \mathbf{1 0} / \mathbf{\Delta} 7$ & $\Delta 8 / \Delta 3$ & $\Delta 10, \Delta 7 \rightarrow \Delta 8$ & Secondary disease & 27 \\
\hline $25-75$ & $26-84$ & Nonlittermate & $\mathrm{gl} / \mathrm{gl}$ & $\Delta 1 / \Delta 1$ or 10 & $\Delta 7 / \Delta 7$ & $\Delta 1 \rightarrow \Delta 7$ & Secondary disease & 40 \\
\hline $26-25$ & $27-00$ & Nonlittermate & bkhfm/gl & $\mathbf{\square} 2 / \mathbf{\Delta} 8$ & $\mathbf{D} 4 / \Delta 3$ & $\mathbf{\Delta} 8 \rightarrow \dot{\Delta} 3$ & Secondary disease & 24 \\
\hline
\end{tabular}

similar reasoning can be applied to $\square 2$ and $\square$ vs. $\square 5$ animals.

\section{Role of non-DLA histocompatibility variables in conditioning the response of radiation chimeras to kidney and skin allografts}

The genetic background of all donors and recipients presented in this study is listed in Table V. 63 dogs were used in 21 consecutive experiments, where irradiated recipients were reconstituted with bone marrow obtained from 8 littermate and 13 nonlittermate donors, and then received renal allografts obtained from 8 other littermate and 13 other nonlittermate sources. 17 marrow donors bore DLA haplotypes derived from the same pedigree origins as the recipients; the DLA-identical haplotypes of four other marrow donors were derived from pedigree origins which had been found previously to be compatible for bone marrow transplantation. Recipients in this category included dog 25-25 (a $\Delta$ 10/ $\mathbf{\Delta} 10$ dog reconstituted with $\Delta 7 / \mathbf{\Delta} 7$ marrow); $\operatorname{dog} 25-90$ (a $\bullet 1 / \mathbf{\square} 2$ dog given $\bullet 1 / \mathbf{\square} 4$ marrow); $\operatorname{dog} 25-73$ (a $\mathbf{\Delta} 10 / \Delta 10$ dog given $\Delta 7$ or $10 / \mathbf{\Delta} 10$ marrow); and $\operatorname{dog} 25-78$ (a $\mathbf{\square}$ or $4 / \mathbf{\Delta} 10$ dog given $\mathbf{\square}$ or $4 / \mathbf{\Delta} 7$ or 10 marrow). As noted in Table $V$, successful engraftment occurred in every instance; there was no evidence of a $\mathrm{GVH}$ reaction in the 14 recipients studied for a period of time (259-1145 days) sufficient to permit this complication to develop. Table VI presents the results of kidney transplantation in irradiated dogs reconstituted with bone marrow obtained from another donor. Two different groups of recipients are pre- sented. The first includes recipients given a DLA haplotype and pedigree-identical renal allograft; the second consists of dogs transplanted with kidneys obtained from donors bearing the same DLA haplotypes as their corresponding recipients, but where such haplotypes were inherited from different pedigree origins. 12 of 14 kidneys transplanted under DLA haplotype- and pedigree-identical conditions currently survive with normal renal function for as long as 949 days; two allografts suffered a chronic rejection at 260 and 385 days, respectively. In contrast, six kidneys transplanted under DLA haplotype-identical but DLA pedigree-different conditions were rejected within 25-56 days, and one kidney survived for 150 days, with death of all recipients in renal failure.

The immunological specificity of the state(s) of allogeneic unresponsiveness produced under the conditions of this study was assessed by challenge of the host with skin allografts obtained from four different sources, including the donor of bone marrow and the kidney donor, another DLA-identical dog sharing the same DLA haplotype pedigree origins as the recipient and the donors of marrow and of kidney, and a DLAincompatible donor. As noted in Table VII, skin allografts obtained from the corresponding donor of marrow currently survive in nine recipients for over 200 days, while skin grafts from the kidney donor currently: survive in similar fashion for 206-236 days in these recipients. In contrast, skin grafts from a third donor bearing pedigree-identical DLA haplotypes were rejected by eight of nine recipients within 13.5-41 days; one graft survived for 84 days and one for 132 days. 
TABLE V

Genetic Background of Donors and Recipients Selected for Bone Marrow and Kidney Allografts and Results of Bone Marrow Transplantation after Supralethal Total Body Irradiation

\begin{tabular}{|c|c|c|c|c|c|c|c|c|c|c|}
\hline \multirow[b]{2}{*}{$\begin{array}{l}\text { Bone } \\
\text { marrow } \\
\text { donor }\end{array}$} & \multirow[b]{2}{*}{$\begin{array}{l}\text { Kidney } \\
\text { donor }\end{array}$} & \multirow[b]{2}{*}{$\begin{array}{c}\text { Recip- } \\
\text { ient }\end{array}$} & \multicolumn{3}{|c|}{ Relationship between } & \multirow[b]{2}{*}{ Donors and recipients } & \multirow[b]{2}{*}{$\begin{array}{c}\text { Bone marrow } \\
\text { donor }\end{array}$} & \multirow[b]{2}{*}{$\begin{array}{l}\text { Kidney } \\
\text { donor }\end{array}$} & \multirow[b]{2}{*}{ Recipient } & \multirow[b]{2}{*}{$\begin{array}{c}\text { Survival of } \\
\text { bone marrow } \\
\text { transplant }\end{array}$} \\
\hline & & & $\begin{array}{l}\text { Bone } \\
\text { marrow } \\
\text { donor }\end{array}$ & $\begin{array}{l}\text { Kidney } \\
\text { donor }\end{array}$ & $\begin{array}{c}\text { Recip- } \\
\text { ient }\end{array}$ & & & & & \\
\hline & & & & & & & & & & days \\
\hline $25-33$ & $25-35$ & $25-36$ & $\mathrm{LM}^{*}$ & L.M & LM & DLA-A7,B13/DLA-A2,B5 & $\bullet 1 / \Delta 7$ & $\bullet \mathbf{l} / \mathbf{\Delta} 7$ & $\bullet \mathbf{l} / \mathbf{\Delta} 7$ & $>1,145$ \\
\hline $25-45$ & $24-91$ & $25-44$ & LM & NLM* & LM & DLA-A7,B13/DLA-A 10,B13 & $\bullet 1 / \square 4$ & $\bullet 1 / \mathbf{\square}$ & $\bullet 1 / \mathbf{\square} 4$ & $>695$ \\
\hline $25-52$ & $25-26$ & $25-43$ & NLM & NLM & NLM & DLA-A10,B13/DLA-A10,B13 & $\square 4 / \square 2$ or 5 & $\square 4 / \square 2$ or 5 & $\square /[2$ or 5 & $>964$ \\
\hline $25-55$ & $25-56$ & $25-42$ & L.M & LM & NLM & DLA-A10,B13/DLA-A10,B13 & $\square 4 / \square 2$ or 5 & प4/[2 or 5 & $\square / / 2$ or 5 & $>948$ \\
\hline $25-89$ & $25-86$ & $25-85$ & LM & LM & LM & DLA-17,B13/DLA-A3,B5 & $\bullet 1 / \nabla 1$ & $\bullet 1 / \nabla 1$ & $\bullet 1 / \nabla 1$ & $>936$ \\
\hline $24-56$ & $25-28$ & $24-64$ & NLM & NLM & NLM & DLA-A10,B13/DLA-A10,B13 & $\square 2$ or $4 / \square 5$ & $\square 4 / \square 5$ & $\square 4 / \square 5$ & $>908$ \\
\hline $26-13$ & $26-09$ & $26-11$ & I.M & $\mathrm{LM}$ & $\mathrm{LM}$ & DLA-A2,B5/DLA-A3,B5 & $\Delta 10 / \nabla 1$ & $\Delta 10 / \nabla 1$ & $\Delta 10 / \nabla 1$ & $>906$ \\
\hline $26-05$ & $26-08$ & $24-63$ & $\mathrm{LM}$ & LM & NLM & DLA-A10,B13/DLA-A10,B13 & $\square 4 / \square 2$ or 4 & $\mathbf{D 4 / \mathbb { 4 }}$ & $\mathbf{D 4 / \mathbb { 4 }}$ & $>903$ \\
\hline $26-40$ & $26-39$ & $26-38$ & LM & LM & LM & DLA-A10,B13/DLA-A10,B13 & $\square 4 / \square 4$ & $\square 4 / \square 4$ & D4/94 & $>704$ \\
\hline $25-22$ & $26-83$ & $25-25$ & LM & NLM & LM & DLA-A2,B5/DLA-A2,B5 & $\Delta \mathbf{A} / \mathbf{\Delta} 7$ & $\Delta 10 / \mathbf{\Delta} 10$ & $\Delta 10 / \Delta 10$ & $>638$ \\
\hline $26-62$ & $26-66$ & $26-77$ & L.M & LM & NLM & DLA-A7,B13/DLA-A 10,B13 & $\bullet 1 / \mathbf{m}$ & $\bullet 1 / \mathbf{\square}$ & $01 / \square 4$ & $>636$ \\
\hline $25-29$ & $22-72$ & $25-90$ & NLM & NLM & NLM & DLA-A7,B13/DLA-A10,B13 & $\bullet 1 / \square 4$ & $\bullet 1 / \square 2$ & $\bullet 1 / \square 2$ & $>579$ \\
\hline $24-48$ & $26-74$ & $26-70$ & NLM & LM & LM & DLA-A7,B13/DLA-A 10,B13 & $\bullet 1 / \square 4$ & $\bullet 1 / \mathbf{4}$ & $\bullet 1 / \mathbf{\square}$ & $>259$ \\
\hline $25-31$ & $22-84$ & $25-41$ & L.M & NLM & L.M & DLA-Al0,B13/DLA-A10,B13 & D4/ 2 or 4 & $\mathbf{D 5 / 0 4}$ & $\square / / 22$ or 4 & $>149$ \\
\hline $25-96$ & $25-97$ & $25-82$ & $\mathrm{LM}$ & $\mathrm{LM}$ & NLM & DLA-A10,B13/DLA-A2,B5 & E4/E9 & $\square 4 / \square 9$ & $\nabla 4 / \square 9$ & $>310$ \\
\hline $25-91$ & $25-92$ & $25-9.3$ & $\mathrm{LM}$ & LM & LM & DLA-A2,B5/DLA-A2,B5 & $\Delta 10 / \Delta 3$ & $\Delta 10 / \Delta 8$ & $\Delta 10 / \Delta 3$ & $>55$ \\
\hline $25-18$ & $2.5-7.5$ & $25-73$ & NLM & LM & LM & DLA-A2,B5/DLA-A2,B5 & $\Delta 7$ or $10 / \Delta 10$ & $\Delta 10 / \Delta 1$ & $\Delta 10 / \Delta 10$ & $>41$ \\
\hline $23-28$ & $25-77$ & $25-78$ & NLM & LM & L.M & DLA-A10,B13/DLA-A2,B5 & $\mathbf{1}$ or $4 / \Delta 7$ or 10 & $\square 1$ or $4 / \Delta 8$ & $\mathbf{D} 1$ or $4 / \Delta 10$ & $>31$ \\
\hline $24-51$ & $24-56$ & $25-98$ & NLM & NLM & NLM & DLA-A 10,B13/DLA-A 10,B 13 & $\mathbf{\square} / \mathbf{\square}$ or 4 & $\square 5 / \square 2$ or 4 & $\square 4 / \square 2$ or 4 & $>30$ \\
\hline $25-47$ & 24-01 & $23-65$ & NLM & NLM & NLM & DLA-A 10,B13/DLA-A2,B5 & $\mathbf{\square} / \mathbf{\Delta} 10$ & ए4/ص8 & 4/D 7 or 10 & $>30$ \\
\hline $24-63$ & $25-31$ & $25-54$ & NLM & NLM & NLM & DLA-A10,B13/DLA-A 10,B 13 & $\square / \mathbf{\square} 2$ & 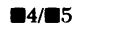 & $\mathbf{\square} / \mathbf{\square} 2$ & $>24$ \\
\hline
\end{tabular}

${ }^{*} \mathrm{LM}=$ littermate; $\mathrm{NLM}=$ nonlittermate.

TABLE VI

Response to Renal Allografts Obtained from a Third-Party Donor in DLA-Identical Bone Marrow Chimeras

\begin{tabular}{|c|c|c|c|c|c|c|c|}
\hline \multirow[b]{2}{*}{ Donor } & \multirow{2}{*}{$\begin{array}{l}\text { Recip- } \\
\text { ient }\end{array}$} & \multirow{2}{*}{$\begin{array}{l}\text { Relation- } \\
\text { ship }\end{array}$} & \multirow[b]{2}{*}{ DLA genotype of donor and recipient } & \multicolumn{2}{|c|}{ Pedigree of } & \multirow{2}{*}{$\begin{array}{l}\text { Source of third-party } \\
\text { renal allograft }\end{array}$} & \multirow{2}{*}{$\begin{array}{l}\text { Kidney } \\
\text { allograft } \\
\text { survival }\end{array}$} \\
\hline & & & & Donor & Recipient & & \\
\hline & & & & & & & days \\
\hline $25-35$ & $25-36$ & $\mathrm{LM}^{*}$ & DLA-A7,B13/DLA-A2,B5 & $\mathbf{O} \mathbf{1} \mathbf{\Delta} 7$ & $\mathbf{1} / \mathbf{\Delta} 7$ & Kidney donor shared the & $>949$ \\
\hline $24-91$ & $25-44$ & NLM* & DLA-A7,B13/DLA-A10,B 13 & $1 / \square 4$ & 1/口4 & same DLA haplotype & $>500$ \\
\hline $25-26$ & $25-43$ & NLM & DLA-A10,B13/DLA-A10,B13 & $\square 4 / \square 2$ or 5 & 口4/口2 or 5 & pedigree origins with & $>768$ \\
\hline $25-56$ & $25-42$ & NLM & DLA-A 10,B13/DLA-A10,B13 & $\square / \square 2$ or 5 & $\square 4 / \square 2$ or 5 & the irradiated recipient. & $>752$ \\
\hline $25-86$ & $25-85$ & $\mathrm{LM}$ & DLA-A7,B13/DLA-A3,B5 & $\mathbf{1} / \nabla 1$ & $\mathbf{1} / \nabla_{1}$ & & $>741$ \\
\hline $25-28$ & $26-64$ & NLM & DLA-A10,B13/DLA-A10,B 13 & $\square 4 / \square 5$ & $\square / \square 5$ & & $>712$ \\
\hline $26-09$ & $26-11$ & LM & DLA-A2,B5/DLA-A3,B5 & $\Delta 10 / \nabla 1$ & $\Delta 10 / \nabla_{1}$ & & $>710$ \\
\hline $26-(08$ & $24-63$ & NLM & DLA-A10,B13/DLA-A10,B13 & $\square 4 / \square 4$ & $\square 4 / \square 4$ & & $>707$ \\
\hline $26-39$ & $26-38$ & LM & DLA-A10,B 13/DLA-A10,B 13 & $\square 4 / \square 4$ & $\square 4 / \square 4$ & & $>508$ \\
\hline $26-83$ & $25-25$ & NLM & DLA-A2,B5/DLA-A2,B5 & $\Delta 10 / \Delta 10$ & $\Delta 10 / \Delta 10$ & & $>442$ \\
\hline $26-66$ & $26-77$ & NLM & DLA-A7,B13/DLA-A 10,B 13 & $1 / \square 4$ & $1 / \square 4$ & & $>440$ \\
\hline $25-97$ & $25-82$ & NLM & DLA-A 10,B 13/DLA-A2,B.5 & $\square 4 / \Delta 9$ & $\mathbf{\square} / \mathbf{\Delta} 9$ & & $>113$ \\
\hline $22-72$ & $25-90$ & NLM & DLA-A7,B13/DLA-10,B13 & $1 / \square 2$ & $1 / \square 2$ & & $385 \ddagger$ \\
\hline $26-74$ & $26-70$ & LM & DLA-A7,B13/DLA-A10,B 13 & $\bullet 1 / \square 4$ & $\bullet 1 / \square 4$ & & $260 \ddagger$ \\
\hline $22-84$ & $25-41$ & NLM & DLA-A10,B13/DLA-A10,B 13 & $\square 5 / \square 4$ & $\square 4 / \square 2$ or 4 & Kidney allograft obtained & $150 \ddagger$ \\
\hline $25-92$ & $25-93$ & LM & DLA-A2,B5/DLA-A2,B5 & $\Delta \mathbf{1 0} / \mathbf{\Delta} 8$ & $\Delta \mathbf{1 0} / \mathbf{\Delta} 3$ & from dogs bearing the & $56 \ddagger$ \\
\hline $25-75$ & $2.5-7.3$ & LM & DLA-A2,B5/DLA-A2,B5 & $\Delta 10 / \Delta 1$ & $\Delta 10 / \Delta 10$ & same DLA haplotypes & $42 \ddagger$ \\
\hline $25-77$ & $25-78$ & $\mathrm{LM}$ & DLA-A 10,B13/DLA-A2,B5 & $\mathbf{D} 1$ or $4 / \mathbf{\Delta} 8$ & $\mathbf{1}$ or $4 / \Delta 10$ & as the recipient, but & $32 \ddagger$ \\
\hline $24-56$ & $25-98$ & NLM & DLA-A10,B13/DLA-A10,B 13 & $\square 2$ or $4 / \square 5$ & $\square 2$ or $4 / \square 4$ & where such haplotypes & $31 \neq$ \\
\hline $24-() 1$ & $23-6.5$ & NLM & DLA-A 10,B13/DLA-A2,B5 & $\square 4 / \Delta 8$ & $\mathbf{\square} / \mathbf{\Delta} 7$ or 10 & were derived from dif- & $31 \ddagger$ \\
\hline $25-31$ & $25-54$ & NLM & DLA-A 10,B13/DLA-A10,B 13 & $\square 4 / \mathbf{m}$ & $\mathbf{\square} / \mathbf{\square} 2$ & ferent pedigree origins. & $25 \ddagger$ \\
\hline
\end{tabular}

* LM = littermate; NLM = nonlittermate.

$\$$ Rejection and death of the recipient. 
TABLE VII

Reactivity to Skin Allografts in DLA-Identical Bone Marrow Chimeras Bearing a Kidney Allograft from Third-Party Donors Whose DLA Haplotypes Were

Derived from the Same Ancestral Origins

\begin{tabular}{|c|c|c|c|c|c|c|}
\hline \multirow[b]{2}{*}{$\begin{array}{l}\text { Bone marrow } \\
\text { donor }\end{array}$} & \multirow[b]{2}{*}{ Kidney donor } & \multirow[b]{2}{*}{ Recipient } & \multicolumn{4}{|c|}{ Survival of skin allografts obtained from } \\
\hline & & & $\begin{array}{l}\text { Bone } \\
\text { marrow } \\
\text { donor }\end{array}$ & $\begin{array}{l}\text { Kidney } \\
\text { donor }\end{array}$ & $\begin{array}{c}\text { Another donor } \\
\text { with same DLA } \\
\text { genotype and } \\
\text { pedigree origins }\end{array}$ & $\begin{array}{l}\text { DLA- } \\
\text { incompatible } \\
\text { donor }\end{array}$ \\
\hline & & & \multicolumn{4}{|c|}{ days } \\
\hline $25-33$ & $25-35$ & $25-36$ & $>236$ & $>236$ & 40 & 16.5 \\
\hline $25-52$ & $25-26$ & $25-43$ & $>206$ & & 41 & 17 \\
\hline $25-55$ & $25-56$ & $25-42$ & $>206$ & $>206$ & $132 *$ & 21 \\
\hline $25-89$ & $25-86$ & $25-85$ & $>233$ & $>233$ & 31 & 24 \\
\hline $24-56$ & $25-28$ & $24-64$ & $>226$ & $>226$ & & 17 \\
\hline $26-13$ & 26-09 & $26-11$ & $>208$ & & 37.5 & 14 \\
\hline 26-05 & $26-08$ & $24-63$ & $>226$ & $>226$ & 13.5 & 13 \\
\hline $26-40$ & $26-39$ & $26-38$ & & & 35 & 25 \\
\hline $25-22$ & $26-83$ & $25-25$ & $>215$ & $>215$ & 84 & 10 \\
\hline $26-62$ & $26-66$ & $26-77$ & $>229$ & $>229$ & 20 & 13 \\
\hline
\end{tabular}

* Chronic rejection with slow progressive shrinkage.

Skin grafts from DLA-incompatible donors were rejected by the same group of dogs within 10-25 days.

\section{DISCUSSION}

The potential biological importance of genetically determined histocompatibility products other than those of the main histocompatibility complex has gained increasing recognition in recent years $(3-5,20-23)$. The continuing absolute dependence of clinical transplantation on immunosuppressive therapy (24), in spite of progress in our understanding of the HLA system (25), have lent particular urgency to the need to develop new in vivo and(or) in vitro techniques applicable to systematic studies of non-main histocompatibility complex determinants in the mammalian host.

Earlier studies of this question in the canine species have provided suggestive evidence for the existence of at least one and possibly more as yet undefined nonDLA histocompatibility locus(i) for which the individual DLA haplotype pedigree records and the associated DLA genotypes can serve as a useful marker in the Cooperstown colony $(3,4,10)$. The studies of Storb and associates $(20,21)$ and of Vriesendorp et al. (22) have provided additional evidence for the activity of such non-DLA histocompatibility complex(es) in canine transplantation. The present study has applied data on the immunogenetics of DLA histocompatibility within the restricted genetic pool of the selectively bred lines of the Cooperstown colony (10) to a systematic program of biological testing of the role of nonDLA histocompatibility determinants in transplantation. The individual pedigree origin of each DLA hap- lotype available for testing within this colony has been used as a marker for the assessment of the allogeneic activity of non-DLA products under conditions of donor-recipient identity for products of the DLA complex. As noted in earlier reports (1-5), bone marrow allografts performed in DLA-identical dogs bearing DLA haplotypes derived from the same pedigree sources have regularly resulted in stable long-term chimerism with no GVH complications. The results observed in dogs bearing the same DLA haplotypes (i.e., haplotypes which type alike but are derived from different pedigree sources) depended upon the particular pedigree origins of the DLA haplotypes involved. Certain donor-recipient combinations $(\boldsymbol{\Delta} 3, \boldsymbol{\Delta} 7$, or $\boldsymbol{\Delta} 10 ; \mathbf{\square} 2$ or 4) produced uniform success of engraftment and stable chimerism; in contrast, others $(\Delta 1$ or $\Delta 8$ to $\Delta 3$, $\Delta 7$, or $\Delta 10 ; \square 2$ or $\square 4$ to $\square$ ) resulted in failures of engraftment, secondary disease, and death of the recipients. When the pedigree origins of the DLA haplotypes in question were traced to their original sources in the Cooperstown colony (Table I), there was no record of a common ancestry between the original dogs bearing compatible histocompatibility pedigrees (dogs C11, 1193, and 12-09 for DLA haplotypes $\Delta 3, \Delta 7$, and $\mathbf{\Delta} 10$; and dogs C11 and 12-06 for $\mathbf{2}$ and $\mathbf{4}$ ). The original dogs bearing incompatible pedigrees were also not known to be related. Taken together with the results of biological testing, these data are consistent with the possibility that the non-DLA histocompatibility products under consideration may be distributed in group fashion in the canine population.

The present study points to the existence in dogs of 
DLA haplotypes which type alike by all currently available in vitro criteria ( $\mathbf{\square}$ and $\mathbf{\square}$, for example), but which differ by a number of histocompatibility determinants that are not yet amenable to laboratory detection. The resulting different "classes" of otherwise DLA-identical haplotypes have been uncovered by in vivo testing with irradiation and bone marrow transplantation in the Cooperstown colony. A close linkage has been observed between the "non-DLA" antigens present in different classes of the same DLA haplotype and the actual products of the DLA complex. This linkage provided the basic marker system for studies of the allogeneic activity of such non-DLA antigens. In the course of these studies, different "classes" of the same DLA haplotype were actually observed within a single litter of Cooperstown dogs. This finding may be of direct relevance to the observation by Amos (26) of the same phenomenon in a population of old order Amish in Indiana, where different forms of the same HLA haplotype (HLA-A2, B12) were shown to occur within a single family unit.

The successful use of the pedigree origins of individual DLA haplotypes in assessing the degree of donorrecipient non-DLA compatibility for bone marrow and kidney transplantation in the Cooperstown colony supports the conclusion that the determinants of such nonDLA products may be genetically linked (or in quasilinkage) with the DLA complex. It must be noted in this regard that findings of HLA or DLA (SD) and (LD) identity between any two given siblings do not constitute a guaranty of donor-recipient identity for the products of all other genetic determinants present on the same chromosome which bears the HLA or the DLA complex. The greater the distance between such other determinants and the DLA complex (as measured by recombinant units), the greater will be the probability that recombinational events involving such determinants will occur. Although a number of studies have postulated that non-DLA genetic determinants are located on chromosomes other than the particular chromosome bearing the DLA complex $(21,22,27)$, the results of the present study suggest that the presence of such determinants on the same chromosome cannot be ruled out at this time (4). This consideration may provide an alternative approach to the understanding of the failure of bone marrow transplants performed under conditions of HLA or DLA genotypic identity in sibling or littermate donor-recipient pairs of subjects.

The results of kidney transplantation presented in this report have provided an additional opportunity to assess the role of non-DLA determinants in the induction of allogeneic unresponsiveness. In earlier studies of the induction of allogeneic unresponsiveness by supralethal total body irradiation and bone marrow transplantation, recipients were allotted a recovery period of 43-120 days after reconstitution with bone marrow, before challenge with a test kidney allograft obtained from the donor of marrow (2). The resulting state of immunological tolerance extended to all donor tissues, including kidney, skin, heart, lung, liver, and pancreas (5), but was limited to tissues obtained from the donor of marrow (3-5). Such individual-specificity, taken together with the hazards of GVH disease in non-DLAidentical donor-recipient combinations, appeared to constitute a serious obstacle to further progress in the application of irradiation and bone marrow transplantation techniques to the production of allogeneic unresponsiveness in large mammalian species. The possibility that the phase immediately after supralethal total body irradiation might constitute a useful period for the induction of allogeneic unresponsiveness (22) has, however, suggested an alternative approach to this question. In this context, irradiated dogs were reconstituted with bone marrow in the usual manner; instead of waiting for 1 or $2 \mathrm{mo}$, however, each dog received a renal allograft from a second DLA- and pedigree-identical donor within 8-12 h after marrow transplantation. Such recipients were rendered tolerant to tissues (skin allografts) from the bone marrow donor, as well as to kidney and skin allografts obtained from the other donor. The recipients retained the ability, however, to reject skin allografts obtained from other DLA- and pedigree-identical donors, pointing to the specificity of the induced state of tolerance and to the host's immunological competence. Under the conditions of this experiment, allogeneic unresponsiveness to tissues from "third party" donors was induced in the recipients only if the donors were DLA-identical, bearing DLA haplotypes derived from the same pedigree origins as the recipient and the donor of marrow. Organs obtained from DLA-identical but pedigree-different donors were uniformly rejected by the recipients. This result suggests that the same broad spectrum of non-DLA histocompatibility determinants operative in affecting the outcome of bone marrow transplantation may also play an important role in conditioning the induction of unresponsiveness to solid tissue allografts in the canine population.

The mechanisms implicated in the production of allogeneic unresponsiveness by irradiation and bone marrow transplantation remain uncertain. The observation that the state of allogeneic unresponsiveness observed in long-term radiation chimeras may be due to an active inhibition of the clonal proliferation required to produce antigen-reactive lymphocytes (5), and recent reports of the ability of suppressor $T$ cells to produce allogeneic unresponsiveness in other species $(28-31)$ point, however, to the possibility that the states of allogeneic unresponsiveness associated with irradiation and marrow transplantation may be related to the 
active production of populations of suppressor cells in the tolerant host.

Taken together, the data suggest that further progress in the understanding of genetically controlled histocompatibility variables other than the currently known products of the main histocompatibility complex is an important prerequisite for renewed advances in transplantation. Supralethal total body irradiation and bone marrow transplantation have provided a useful in vivo test system for the analysis of non-DLA alloantigens in the canine species. Further progress in this area would appear to await the development of new in vitro techniques for the detection and characterization of non-main histocompatibility complex determinants in various mammalian species, including man.

\section{ACKNOWLEDGMENTS}

This work was supported in part by The Whitehall Foundation and by grant AI-10658-05 from the National Institutes of Health, Bethesda, Md.

\section{REFERENCES}

1. Rapaport, F. T., F. D. Cannon, D. A. Blumenstock, K. Watanabe, and J. W. Ferrebee. 1971. Long term survival of bone marrow and kidney allografts in irradiated DLA identical dogs. Transplant. Proc. 3: 1337-1342.

2. Rapaport, F. T., F. D. Cannon, D. A. Blumenstock, K. Watanabe, and J. W. Ferrebee. 1972. Induction of unresponsiveness to canine renal allografts by total body irradiation and bone marrow transplantation. Nat. New Biol. 235: $190-192$.

3. Rapaport, F. T., K. Watanabe, F. D. Cannon, N. Mollen, D. A. Blumenstock, and J. W. Ferrebee. 1972. Histocompatibility studies in a closely bred colony of dogs. IV. Tolerance to bone marrow, kidney and skin allografts in DLA-identical radiation chimeras. J. Exp. Med. 136: 1080-1087.

4. Rapaport, F. T., A. Ozaki, F. D. Cannon, N. Mollen, D. Blumenstock, J. H. Ayvazian, and J. W. Ferrebee. 1973. Parameters of allograft unresponsiveness in canine radiation chimeras, with particular reference to the possible existence of three closely linked genetic systems relevant to bone marrow transplantation. Transplant. Proc. 5: 845852.

5. Rapaport, F. T., H. S. Lawrence, R. J. Bachvaroff, F. D. Cannon, D. A. Blumenstock, N. Mollen, J. H. Ayvazian, and J. W. Ferrebee. 1975. Histocompatibility studies in a closely bred colony of dogs. V. Mechanisms of cellular adaptation in long-term DLA-identical chimeras. J. Exp. Med. 142: 120-138.

6. Rapaport, F. T., A. D. Boyd, F. C. Spencer, R. R. Lower, J. Dausset, F. D. Cannon, and J. W. Ferrebee. 1971. Histocompatibility studies in a closely bred colony of dogs. II. Influence of the DLA system of canine histocompatibility upon the survival of cardiac allografts. J. Exp. Med. 133: $260-274$.

7. Blumenstock, D. A., H. Kazem, C. A. Hales, F. D. Cannon, R. Zumwalt, and J. W. Ferrebee. 1974. Allotransplantation of lung without immunosuppression after transplantation. I. Staged transplantation of bone marrow and lung. Transplantation (Baltimore). 18: 336-342.
8. Ranson, J. H. C., K. Eng, F. F. Becker, F. T. Rapaport, and S. A. Localio. 1974. Auxiliary transplantation of liver, duodenum and pancreas. Surg. Forum. 25: 389-391.

9. Ranson, J. H. C., K. Eng, S. A. Localio, and F. T. Rapaport. 1975. Allotransplantation in studies of hepatic physiology. Transplant. Proc. 7 (Suppl. 1): 759-762.

10. Dausset, J., F. T. Rapaport, F. D. Cannon, and J. W. Ferrebee. 1971. Histocompatibility studies in a closely bred colony of dogs. III. Genetic definition of the DLA system of canine histocompatibility, with particular reference to the comparative immunogenicity of the major transplantable organs. J. Exp. Med. 134: 1222-1237.

11. Vriesendorp, H. M., E. D. Albert, J. W. Templeton, S. Belotsky, B. Taylor, D. A. Blumenstock, R. W. Bull, F. D. Cannon, R. B. Epstein, J. W. Ferrebee, H. Grosse-Wilde, C. Hammer, K. Krumbacher, S. Leon, P. Meera Khan, M. R. Mickey, M. Motola, F. T. Rapaport, R. Saison, H. Schnappauf, S. Scholz, M. L. Schroeder, R. Storb, R. Wank, D. L. Westbroek, and A. Zweibaum. 1976. Joint Report of the 2nd International Workshop on Canine Immunogenetics. Transplant. Proc. 8: 289-311.

12. Epstein, R. B., R. Storb, H. Ragde, and E. D. Thomas. 1968. Cytotoxic typing antisera for marrow grafting in littermate dogs. Transplantation (Baltimore). 6: 45-58.

13. Mollen, N., D. St. John, F. D. Cannon, and J. W. Ferrebee. 1968. Lymphocyte typing in allografted beagles. Transplantation (Baltimore). 6: 939-940.

14. Bachvaroff, R., F. T. Rapaport, F. D. Cannon, N. Mollen, D. A. Blumenstock, J. H. Ayvazian, and J. W. Ferrebee. 1973. Relative roles of genetic histocompatibility determinants in bone marrow transplantation.J. Exp. Hematol. 1: 233-237.

15. Bachvaroff, R., A. Ozaki, F. D. Cannon, N. Mollen, D. A. Blumenstock, J. H. Ayvazian, J. W. Ferrebee, and F. T. Rapaport. 1973. Phenotypic expression of the main histocompatibility complex (DLA) in randomly selected mongrel dogs. I. Serologically detectable (SD) DLA antigens and mixed leucocyte culture (MLC) reactivity. Transplant. Proc. 5: 1561-1565.

16. Ozaki, A., R. Bachvaroff, F. D. Cannon, N. Mollen, D. A Blumenstock, J. H. Ayvazian, J. W. Ferrebee, and F. T. Rapaport. 1973. Phenotypic expression of the main histocompatibility complex (DLA) in randomly selected mongrel dogs. II. Serologically detectable (SD) compatibility, MLC reactivity and skin allograft survival. Transplant. Proc. 5: $1781-1783$.

17. Bachvaroff, R., A. Ozaki, F. D. Cannon, N. Mollen, D. A. Blumenstock, J. H. Ayvazian, J. W. Ferrebee, and F. T. Rapaport. 1973. Phenotypic expression of the main histocompatibility complex (DLA) in randomly selected mongrel dogs. III. Inhibition of the mixed leucocyte culture reaction during and after sensitization to skin allografts. Transplant. Proc. 5: 1863-1868

18. Hartzman, R. J., M. Segall, M. L. Bach, and F. H. Bach. 1971. Histocompatibility matching. VI. Miniaturization of the mixed leukocyte culture test: a preliminary report. Transplantation (Baltimore). 11: 268-273.

19. Rapaport, F. T., T. Hanaoka, T. Shimada, F. D. Cannon, and J. W. Ferrebee. 1970. Histocompatibility studies in a closely bred colony of dogs. I. Influence of leukocyte group antigens upon renal allograft survival in the unmodified host. J. Exp. Med. 131: 881-893.

20. Storb, R., R. H. Rudolph, H. J. Kolb, T. C. Graham, E. Mickelson, V. Erikson, K. G. Lerner, H. Kolb, and E. D. Thomas. 1973. Marrow grafts between DLA matched canine littermates. Transplantation (Baltimore). 15: 92100 . 
21. Storb, R., P. L. Weiden, T. C. Graham, and E. D. Thomas. 1976. Studies of marrow transplantation in dogs. Transplant. Proc. 8: 545-549.

22. Vriesendorp, H. M., C. Zurcher, and D. W. van Bekkum. 1975. Engraftment of allogeneic dog bone marrow. Transplant. Proc. 7: 465-468.

23. Grebe, S. C., and J. W. Streilein. 1976. Graft-versus-host reactions: a review. Adv. Immunol. 22: 119-221.

24. Starzl, T. E. 1975. The flaws of immunosuppression in organ transplantation today. Transplant. Proc. 7 (Suppl. 1): 585-588.

25. Dausset, J., and F. T. Rapaport. 1977. Immunology and genetics of transplantation. In Seminars in Nephrology. E. Lovell Becker, editor. John Wiley \& Sons, Inc., New York. 97-138.

26. Amos, D. B. 1976. Matching for donor-host compatibility for bone marrow transplantation. Transplant. Proc. 8: $687-692$.
27. Storb, R., P. L. Weiden, M. L. Schroeder, T. C. Graham, K. G. Lerner, and E. D. Thomas. 1976. Marrow grafts between canine littermates homozygous or heterozygous for lymphocyte-defined histocompatibility antigens. Transplantation (Baltimore). 21: 299-306.

28. Jirsch, D. N., N. Kraft, and E. Diener. 1974. Tolerance induction to a heterotopic cardiac allograft in the irradiated reconstituted mouse. Transplantation (Baltimore). 18: $155-162$.

29. Gershon, R. K., E. M. Lance, and K. Kondo. 1974. Immunoregulatory role of spleen-localizing thymocytes. $J$. Immunol. 112: 546-554.

30. Droege, W. 1975. Immunosuppressive effect of syngeneic thymus cells on allograft rejection. Proc. Natl. Acad. Sci. U. S. A. 72: 2371-2374.

31. Brent, L., and P. J. Kilshaw. 1976. Humoral factors in specific unresponsiveness to transplantation antigens. Transplant. Proc. 8: 209-215. 